\title{
Las reclamaciones previas y los recursos gubernativos en la vigente legislación local española
}

RECURSOS DE ALZADA

Hace más de un cuarto de siglo se decía en el notable preámbulo que precedia al Estatuto municipal de Calvo Sotelo, que, en un régimen centralizado, todos los acuerdos municipales pueden ser revocados por la autoridad gubernativa, que resulta así superior a los Ayuntamientos y a éstos se les convierte en simple rueda del engranaje administrativo del Estado. En un régimen autonomista, por el contrario, las autoridades gubernativas deben carecer de la menor facultad respecto a la vida municipal ; consiguientemente, los acuerdos de los Ayuntamientos sólo podrán ser impugnados ante el Poder judicial, supremo definidor del derecho conculcado, en todos los órdenes.

La nueva Ley de Régimen local, en su texto articulado de 16 de diciembre de 1950, mantiene lo fundamental del régimen jurídico establecido a partir del día 8 de marzo de 1924, declarando que los actos y acuerdos de autoridades y Corporaciones locales, con excepción de aquellos a los que la Ley asigna recurso especial, causan estado en vía gubernativa, y podrán ser objeto de recurso contencioso-administrativo ante el Tribunal provincial, tanto por lesión de derecho administrativo del recurrente, como por incom- 
petencia, vicio de forma o violación de disposiciones legales administrativas, si el recurrente tiene interés directo en el asunto.

Permanece, pues, según expresa manifestación del Ministro de la Gobernación en su discurso de presentación a las Cortes del proyecto de la presente Ley, casi inalterado el control jurisdiccional contencioso-administrativo, salvo en materia electoral y de multas impuestas por los Alcaldes, que será gubernativo. La primera salvedad en su opinión, por su índole política, y la segunda-las multas-porque invita a ello el deseo de sustraer a la jurisdicción de los jueces una materia que no concierne al Derecho privado o común, sino al Derecho público.

Estas dos excepciones están comprendidas dentro de la nomenclatura adoptada para los recursos establecidos en la Ley entre los que denomina recursos administrativos; incluyendo en esta sección - los de alzada ante los Gobernadores civiles, siendo recurribles en tal sentido las providencias que dicten los Presidentes de las Corporaciones locales como delegados de la Administración central, los acuerdos de los Alcaldes o Ayuntamientos resolutivos de competencia, y las multas impuestas por las autoridades locales, que no tengan señalado recurso especial.

Asimismo se regulan los recursos de alzada ante el Ministro de la Grobernación, pudiendo recurrirse con este carácter las resoluciones que dicten los Gobernadores civiles, en las cuestiones que se produzcan sobre incapacidades, excusas o incompatibilidades de los miembros de las Corporaciones locales, y ante el Ministerio correspondiente los acuerdos que adopten dichas autoridades provinciales, en relación a las providencias dictadas por las autoridades municipales en su calidad de delegadas del Gobierno en su término respectivo; estableciéndose por último el recurso de alzada ante el Ministro de la Gobernación, contra las resoluciones dictadas por los Gobernadores civiles en las cuestiones de competencia suscitadas entre las autoridades o Corporaciones de su provincia, o en aquellas otras en las que resuelvan suscitar o no suscitar una competencia a los Tribunales de Justicia o desistir de una positiva que hubieran planteado.

Aparte de los recursos de alzada anteriormente enunciados, se 
prevén en la nueva Ley otros varios de esta naturaleza, como procedimiento normal de revisión superior gubernativa de las decisiones de las Entidades y Organismos de la Administración local. Así vemoṣ que, en el número 2 del artículo 56, se establece que, contra las inclusiones, exclusiones o calificación de los habitantes en el empadronamiento, los interesados podrán reclamar ante el Alcalde y contra el acuerdo de éste se dará recurso de alzada ante el Gobernador civil de la provincia. Declarándose asimismo recurribles en alzada por el artículo 155, ante el Ministro de la Gobernación, los acuerdos que adopte en materia de su competencia la Comisión Central de Urbanismo.

En el título tercero del Libro III de la Ley, que trata de los funcionarios de Administración local, se prescribe de igual forma este recurso en el número 5 del artículo 336, que dispone serán recurribles ante el Ministro de la Gobernación, las sanciones de destitución o separación definitiva del servicio, que imponga la Dirección General de Administración Local ; y según el número 2 del artículo 339, contra los nombramientos acordados por la misma, se podrá recurrir en alzada durante el término de quince días ante el propio Ministerio.

Se consigna de nuevo este recurso en el título quinto del propio Libro, al desenvolver el régimen jurídico de las Corporaciones locales, y regular la suspensión de acuerdos y ejercicio de acciones, de que se ocupa el capítulo primero del mismo; estableciéndose en el número 2 del artículo 364, que, contra la resolución del Gobernador civil (suspendiendo los acuerdos de los Presidentes de las Corporaciones locales, en los tres casos referidos en el número primero), podrán dichos Presidentes interponer el recurso de alzada ante el Ministerio de la Gobernación, por sí o en cumplimiento de acuerdo de las respectivas Corporaciones. Si no recayese decisión ministerial dentro de los treinta días siguientes a la interposición del recurso, se entenderá revocada la suspensión.

Dándosele cabida en este Libro, por último, en el capítulo tercero de dicho título, que define la responsabilidad de las Entidades, Organismos, autoridades y funcionarios de Administración local ; prescribiéndose en el número 2 del artículo 419, al hacer re- 
ferencia a la facultad de los Gobernadores civiles para corregir a los Presidentes de las Corporaciones locales, por falta de celo en el ejercicio de funciones delegadas de la Administración general, que la imposición de las multas se hará por medio de acuerdo razonado que especifique concretamente los motivos de la sanción, y será recurrible, previa su consignación, en término de diez días, ante el Ministro de la Gobernación, que resolverá sin ulterior recurso.

Queda por el contrario mucho más restringida en el Libro IV, - Haciendas locales-del texto articulado de la Ley, la utilización de los recursos de alzada, quizá porque la materia económica, dada su especial naturaleza, susceptible de una mayor fricción de intereses, debe resultar por completo alejada de cuanto pueda suponer encono político o mera pugna de criterios personalistas, de la que no siempre puede desprenderse la simple vía gubernativa al ser sustraídas sus decisiones a la revisión del control jurisdiccional. En su consecuencia se admite solamente su ejercicio en dos ocasiones: una, de la que trata el número primero del artículo 582, al establecer que podrá entablarse por el Ayuntamiento interesado o por los contribuyentes del término municipal, contra el acuerdo que la Delegación de Hacienda dicte en los expedientes instruidos para alterar el orden de imposición de las exacciones municipales, y el recurso que determina el artículo 697, que es la segunda ocasión referida, pues no es otro sino el de alzada ante el Ministerio de. Hacienda, si bien contra cuya resolución podrá interponerse recurso contencioso-administrativo.

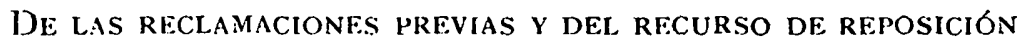

La sección tercera del capítulo segundo del Libro III de la vigente Ley de Régimen local se ocupa de la materia propia del presente epígrafe, aunque circunscribiendo el concepto de reclamación previa en el artículo 376 al trámite obligado para ejercitar acciones civiles contra las autoridades y Corporaciones locales, sien- 
do lo cierto que en múltiples lugares de la mismạ se utiliza igual denominación sin la adjetivación, como procedimiento normal para instar la modificación o rectificación de acuerdos o decisiones municipales o provinciales, perturbadores del derecho de los particulares, en las diferentes esferas o asuntos en los que éstos pueden considerarse afectados por aquéllos; disponiéndose por el artículo 377 , que, para interponer recursos o reclamaciones en los demás casos, contra actos o acuerdos de las autoridades o Corporaciones locales, será requisito indispensable el previo recurso de reposición ante la autoridad o Corporación que los hubiere adoptado.

Pretende, no obstante, la Ley, a nuestro parecer, con las prescripciones contenidas en los artículos citados, delimitar por el primero el ámbito propio de la vía gubernativa, volviendo de nuevo a darle actualidad en la esfera local, como medio de llegar a una definición de sus peculiares características administrativas, desdibujadas en la anterior legislación municipal, a partir de la implantación por la misma del recurso de reposición que era utilizado en el procedimiento civil, y que es adoptado por ella, estableciendo su diferenciación con éste, como antecedente necesario para determinar cuál ha de ser su contenido y finalidad, lo que efectúa el segundo de dichos preceptos legales. Si bien empleando una expresión indistinta para los restantes casos de aplicación del recurso de reposición, que por su amplitud y ambigüedad entendemos puede prestarse a confusión, y que obliga seguidamente al legislador a reconocer ciertas excepciones a la regla general de interposición ; una de carácter absoluto, por lo que afecta a las denegaciones tácitas, que podrán ser impugnadas directamente ante los tribunales o autoridades competentes, y otras de forma relativa, declarando potestativo dicho recurso, en materia de multas, en las reclamaciones económica-administrativas y demás referentes a las Haciendas locales.

Pero no es ésta la única razón que nos hace dudar de la adecuada interpretación que en la práctica pueda darse a este artículo 377 de la Ley de Régimen local, sino el estimar en armonía al propio texto del artículo 374, que se invierten los términos al decir, como lo hace el referido artículo, que el recurso de reposi- 
ción será requisito indispensab!e para interponer recursos o reclamaciones, ya que es de suponer que la petición o reclamación debe preceder a este trámite previo que pone fin a la mencionada vía gubernativa. Aplicándose precisamente en este artículo 374 la doctrina del silencio administrativo como garantía concedida a los particulares frente a la inactividad de la Administración local para resolver cualquier simple instancia o solicitud, dando lugar por este motivo a exceptuar del recurso de reposición las denegaciones tácitas, a las que hicimos referencia.

Por consiguiente, los acuerdos que desestimen las restantes reclamaciones sobre las que resuelvan las Corporaciones locales, y que en tan elevado número se consignan como susceptibles de ser interpuestas ante las mismas en su extenso articulado será contra los que cabe ejercitar dicho recurso cuyo fallo abre el camino a la vía jurisdiccional, sin que acertemos a comprender a qué otra clase de reclamaciones puede aludir la Ley con exclusión de las previas para el ejercicio de acciones civiles que no sean las indicadas.

Examinaremos ahora la regulación que hacen de la naturaleza procesal del recurso de reposición la Ley de Régimen local y el Reglamento de Organización, Funcionamiento y Régimen jurídico de las Corporaciones locales de 17 de mayo de 1952.

Es bien concisa esta parte normativa de la Ley, y aunque tampoco puede decirse que el Reglamento le dedique un mayor articulado, entendemos que es el suficiente para desarrollar y puntualizar el contenido de sus preceptos.

Pero con todo ello justo es admitir que representa un avance estimable en la evolución del proceso administrativo, dando forma a este recurso que, tras distintas vicisitudes en las diversas ramas del Derecho español, llega al municipal sin apenas conocerse otra cosa sobre sus caracteres específicos que ser denominado de reposición. En efecto, se han incorporado a la legislación local promulgada principios reconocidos anteriormente por la doctrina, pero que aun no habían tenido cauce ni realidad en nuestro Derecho positivo de los últimos tiempos, a pesar de su estudio y aceptación por los más autorizados tratadistas de esta especialidad jurídica.

Bajo este aspecto, como valiosa aportación, supone una intere- 
sante novedad de la Ley exceptuar del recurso de reposición, como lo hace en el artículo 378, las denegaciones tácitas, puesto que hasta su publicación fué bien enconada la controversia en torno a esta cuestión, que toma como base la moderna teoría del silencio administrativo.

Contribuyó a esta disparidad de opiniones la propia jurisprudencia, estableciendo primeramente la necesidad de un acuerdo real $\mathrm{y}$ efectivo, para ser recurrible en reposición, criterio que rectifica con posterioridad al prescribir dicho recurso contra las denegaciones tácitas; si bien nos cabe la satisfacción de haber mantenido la primitiva posición del Tribunal Supremo, cuando se elogiaba y compartía sin reservas la adoptada últimamente.

Decíamos con este motivo en nuestro trabajo (1) que, por mucho que se quiera forzar la argumentación, no es posible equiparar un acuerdo municipal en el sentido propio y material de la palabra, con la denegación presunta estudiada ; a todo lo más que podemos llegar en el terreno de la concesión a este respecto es admitir que la Administración municipal, al no contestarle al particular sobre una determinada petición, plantea la presunción de que la ha desestimado; pero también sabemos, por haberlo aprendido en nuestra práctica profesional, que esta actitud negativa de la Corporación o autoridad municipal puede obedecer muy bien, más que a otra cosa, a simple abandono de las personas encargadas de resolver, bien se trate de los mismos concejales o de los funcionarios que hayan de informar previamente con relación al asunto que se reclama, y no lo hagan con la diligencia debida, dando con ello motivo a que se produzca por mera negligencia la situación embarazosa para el interesado, de no saber a qué atenerse por la falta de contestación a su demanda o solicitud, si a una franca oposición a la misma o, por el contrario, al propósito subrepticio de hacerle desistir por cansancio de su derecho.

Esta nueva orientación que dejamos consignada es recogida y desenvuelta por el citado Reglamento de Organización y Régimen

(1) El recurso de reposición en la legislación municipal. "Revista General de Derechon.-Valencia, enero 1950, página 4. 
jurídico, en sus artículos 225 y 334 ; prescribiendo en el primero que no se considerará existente el acuerdo que no conste explícita y terminantemente en el acta que corresponda a su adopción : pudiendo ser subsanada la omisión de cualquier acuerdo si, en virtud de escrito documentado dèl Secretario, así lo aprueba la Corporación antes de que se cierre el acta de la sesión siguiente a la en que hubiere sido adoptado. En el segundo de dichos preceptos legales establece que las autoridades y Corporaciones locales estarán obligadas a resolver sobre las peticiones que se les dirijan o a declarar, en su caso, los motivos de no hacerlo. El silencio de dichas autoridades o Corporaciones se interpretará como denegatorio de la pretensión ante ellas deducida, salvo los casos que se rijan por presunciones distintas. Teniendo como antecedente los artículos 273 del referido Estatuto municipal y 13 del Reglamento de Procedimiento en materia municipal de 23 de agosto de 1924, considerando incursos en responsabilidad gubernativa a los Alcaldes y autoridades de todos los órdenes que incurriesen en demora injustificada en la tramitación y resolución de los recursos que en la Ley tienen asignados plazos fijos.

Completando esta materia, el Reglamento de 17 de mayo de 1952 al disponer en el artículo 336 que, contra las denegaciones tácitas del recurso de reposición, se dará el contencioso-administrativo, con arreglo al párrafo segundo del artículo 388 de la Ley de Régimen local, y contra las demás denegaciones tácitas, el que - señala el párrafo tercero del mismo precepto.

En cuanto a la estructura procesal del recurso de reposición, se incluyen lo mismo en la Ley que en el repetido Reglamento de Régimen jurídico importantes innovaciones con relación a la legislación municipal hasta ahora vigente.

Por lo que afecta a la primera, define en el artículo 379 quién es el sujeto de este recurso, declarando que sólo podrá ser interpuesto por las personas que puedan ejercitar los recursos subsiguientes al mismo previstos en esta Ley. Precepto que se hacía muy necesario por no existir antecedentes sobre el caso en las anteriores regulaciones de la Administración local, y aunque por analogía eran de aplicación las normas generales del procedimiento 
civil, teniendo en cuenta las peculiaridades del administrativo en su especialidad municipal, resultaba difícil dar una regla exacta de capacidad para su interposición. Se imponía la distinción clásica entre capacidad jurídica y capacidad de obrar o bien procesa! en este supuesto; pero tratándose del proceso administrativo hacía falta, además, para ser parte en el mismo, representar una causa legítima que había de quedar supeditada a la naturaleza del recurso que se hubiera de interponer o acción a ejercitar, tomando como base, según la Ley municipal de 31 de octubre de 1935, la lesión de un derecho civil o administrativo, o bien, en otros casos, ia violación material de leyes o disposiciones administrativas, vicio de forma o incompetencia por razón de la materia, y en los cuales sería parte legítima la persona individual o jurídica que invocase un interés agraviado, sin que la invocación tuviera que ser sometida a prueba.

Ha sido, en su virtud, una lógica y acertada solución a este vacío procesal la ofrecida por la Ley de Régimen local en el artículo comentado.

Con referencia al texto reglamentario, hemos de señalar como de mayor interés el contenido de los artículos 356 y 357, determinándose en el primero la clase de sesiones en las que el Ayuntamiento pleno pō̄rá resolver los recursos de reposición interpuestos contra sus acuerdos, y en el segundo, la manera expresa que éstos han de adoptar para su presentación, estableciendo que los mismos se formularán por escrito, en forma clara, con expresión de las razones que estime el reclamante, preceptos en que las apoye y alcance de sus pretensiones, a fin de que la Corporación pueda examinar la resolución impugnada y confirmarla, revocarla o reformarla.

Dándose con ellos solución a distintos problemas de técnica jurídica, que el silencio de la anterior legislación municipal tenía planteados sobre este particular. Si bien el de trascendencia procesal más acusada a nuestro juicio quedó suficientemente aclarado y resuelto, en principio, por la Bas 56 de la Ley de Régimen local de 17 de julio de 1945, actualmente artículo 369 del texto articulado, al prescribir que las autoridades $y$ Corporaciones loca- 
les no podrán revôcar sus propios actos o acuerdos declaratorios de derechos subjetivos o que hubieran servido de base a una resolución judicial, salvo al resolver recursos de reposición. Podrán, sin embargo, rectificarse los errores materiales de hecho.

Se trataba, en efecto, de una cuestión que constituía por sí una seria limitación de la potestad de revocación de sus decisiones, que debía ser privativa de la competencia de aquéllas; teniendo como precedente legislativo el artículo 294 del Reglamento de la Subsecretaría de Justicia de 9 de julio de 1917, en el que se establecía que la Administración no puede volver sobre sus propios acuerdos cuando éstos han originado derechos, ni revocar, anular o modificar sus resoluciones, sino someterlas a revisión en la vía contencioso-administrativa ante el competente Tribunal.

Representa, por tanto, la facultad de revocación reconocida por los nuevos preceptos legales citados, merced a la resolución del recurso de reposición, como dijimos en otra ocasión (2), la consagración en el derecho positivo municipal de lo que hasta ahora sólo había constituído una aspiración de carácter doctrinal.

Exige, en su virtud, el número uno del mencionado artículo 357 del Reglamento de Organización y Régimen jurídico para que la Corporación pueda examinar la resolución impugnada, que en el escrito de recurso se expresen las razones que estime el reclamante, preceptos en que las apoye y alcance de sus pretensiones.

Con lo cual ordena la forma escrita y que sea clara, debiendo tener el mismo una fundamentación moral y jurídica, siguiendo la opiniớn sustentada por el Tribunal Supremo, particularmente en las Sentencias de 2 de octubre de 1931 y 29 de enero de 1940, haciendo constar que "... si no se acredita la presentación del recursó de reposición, el acuerdo municipal no ha causado estado por no haberse agotado la vía gubernativa, y la Sala deberá apreciar la excepción de incompetencia y no entrar en el fondo de la cuestión, aunque ésta adolezca de vicios esenciales del procedimienton.

(¿) Lil recurso de reposición en la legislación municipal. "Revista General de Derecho".-Valencia, octubre 1949, página 573 y siguientes. 
Cunfirma, por último, el número dos del propio artículo 357 el benévolo criterio mantenido por el Tribunal Supremo en lo que afecta a los requisitos formales que han de ser tenidos en cuenta para la presentación del recurso de reposición, prescribiendo sin perjuicio de las disposiciones del apartado primero que los organismos locales no podrán rechazar los escritos en: que se interpongan estos recursos, aduciendo deficiencias de fondo o de forma.

Antes de terminar el examen sobre la nueva reglamentación local del recurso de reposición hemos de indicar como otro acierto. de la misma la previsión establecida en el artículo 358 del repetido Reglamento de Organización y Régimen jurídico, declarando que la interposición del expresado recurso cuando fuere potestativo, de conformidad al artículo 380 de la Ley, interrumpirá los. plazos para impugnar los acuerdos hasta que se resuelva la repa sición o quede tácitamente desestimada en los términos que señala el artículo 377 de la misma; pues gracias a ella pueden evitarse los perjuicios que en otro caso se le originarían al recurrente de cumplirse a la letra los preceptos del artículo 475 del Reglamento general vigente para la ejecución de la Ley de lo Contenciosoadministrativo de 22 de junio de 1894, actualmente texto refundido aprobado por Decreto de 8 de febrero de 1952, y en el que se dispone que el interesado al que se le desestimara por incompetencia: de la autoridad recurrida, el recurso gubernativo interpuesto en vez del contenciosoadministrativo para interponer éste sólo podrá utilizar el plazo que reste descontado el empleado en la vía gubernativa, caducando su derecho si hubiere aquél transcurrido por completo; no perjudicando al recurrente de estimarse competentela autoridad administrativa el tiempo invertido en la sustanciación del recurso, aunque sí el que invirtió hasta interponerlo, si después se anulase todo lo actuado por el 'Tribunal de lo Contencioso. administrativo.

Sirviendo, además, la doctrina que se establece en el referido. artículo 358 del Reglamento de Organización y Régimen jurídico para armonizar el contenido del artículo anteriormente citado con lo dispuesto en el artículo 381 de`la Ley de Régimen local, en cuanto a la prohibición de que los actos y acuerdos de las auto- 
ridades o Corporaciones puedan ser impugnados simultáneamente por una misma persona en diferentes vías; sin perjuicio de admitir la expresa reserva del derecho del interesado a ejercitar acción distinta de la utilizada para el caso de que ésta no prospere, entendiéndose preparado en tiempo hábil el procedimiento correspondiente.

José AlCízar Olalia, Doctor en Derecho

Secretario del Ayuntamiento de Loja 